\title{
A HISTÓRIA ORAL E SUA CONTRIBUIÇÃO PARA A RECUPERAÇÃO DA MEMÓRIA E DA HISTÓRIA DO ENSINO TÉCNICO E PROFISSIONAL AGRÍCOLA EM JACAREÍ- SP
}

\author{
Júlia Naomi Kanazawa \\ Universidade Estadual de Campinas \\ juliankanazawa@gmail.com
}

\begin{abstract}
RESUMO
A história oral tem sido empregada nas pesquisas sobre a educação profissional paulista como uma das metodologias para recuperar a memória e a história do ensino técnico. Neste artigo apresentam-se as possibilidades de sua utilização nos estudos, especialmente quando se aborda a representação discente do curso de Iniciação Agrícola em Jacareí, SP, na então Escola Profissional Agrícola e Industrial Mista Cônego José Bento, em relação à cultura escolar de uma determinada época, como as disciplinas, os professores, os espaços e os recursos pedagógicos. Espera-se ressaltar, assim, as potencialidades desse procedimento nas investigações da educação do público escolar feminino no ensino agrícola, parte integrante do patrimônio educativo.
\end{abstract}

Palavras-chave: História Oral. Ensino profissional agrícola. Turma feminina.

\section{THE ORAL HISTORY AND ITS CONTRIBUTION TO THE RECOVERY OF THE MEMORY AND THE HISTORY OF THE TECHNICAL AND AGRICULTURAL EDUCATION IN JACAREÍ-SP}

\begin{abstract}
Oral history has been used in research on professional education in São Paulo as one of the methodologies for recovering the memory and history of technical education. This article presents the possibilities of its use in the studies, especially when it is approached the student representation of the course of Agricultural Initiation in Jacareí, SP, in the then Mixed Agricultural and Industrial Vocational School Cônego José Bento, in relation to the school culture of a determined period, such as the disciplines, teachers, spaces and pedagogical resources. It is hoped to highlight, therefore, the potential of this procedure in the investigations of the education of the female school audience in professional agricultural teaching, an integral part of the educational patrimony.
\end{abstract}

Keywords: Oral History. Professional agricultural teaching. Female group.

\section{LA HISTORIA ORAL Y SU CONTRIBUCIÓN PARA LA RECUPERACIÓN DE LA MEMORIA Y LA HISTORIA DE LA ENSEÑANZA TÉCNICA Y PROFESIONAL AGRÍCOLA EN JACAREÍ-SP}

\section{RESUMEN}

La historia oral ha sido empleada en las investigaciones sobre la educación profesional paulista como una de las metodologías para recuperar la memoria y la historia de la enseñanza técnica. En este artículo se presentan las posibilidades de su utilización en los estudios, especialmente cuando se aborda la representación discente del curso de Iniciación Agrícola en Jacareí, SP, en 
la entonces Escuela Profesional Agrícola e Industrial Mixta Cônego José Bento, en relación a la cultura escolar de una determinada época, como las disciplinas, los profesores y los espacios. Se espera resaltar, así, las potencialidades de ese procedimiento en las investigaciones de la educación del público escolar femenino en la enseñanza agrícola, parte integrante del patrimonio educativo.

Palabras clave: Historia Oral. Enseñanza profesional agrícola. Mujer femenina.

\section{L'HISTOIRE ORAL ET SA CONTRIBUTION À LA RECUPERATION DE LA MÉMOIRE ET DE LA HISTORIQUE PROFESSIONNEL DE L'EDUCATION TECHNIQUE ET AGRICOLE À JACAREÍ-SP}

\section{RÉSUMÉ}

L'histoire orale a été utilisée dans le cadre de recherches sur l'enseignement professionnel à São Paulo comme l'une des méthodes de récupération de la mémoire et de l'histoire de l'enseignement technique. Cet article vise à présenter les possibilités pour son utilisation dans les études, en particulier quand il aborde à la représentation des étudiants du cours d'initiation agricole de Jacareí, SP, en relacion avec la culture scolaire d'un temps donné, tels que les disciplines, les espaces et les ressources pedagógicos. On espère donc mettre en évidence le potentiel de cette procédure dans les enquêtes sur l' éducation en général, et en particulier l'école $\mathrm{du}$ public scolaire féminin dans l'enseignement agricole, partie intégrante du patrimoine éducation.

Mots-clés: Histoire orale. Enseignement agricole professionnel. Groupe de femmes.

\section{INTRODUÇÃO}

Nas pesquisas sobre a educação profissional paulista, o grupo de docentes tem empreendido a história oral como metodologia para recuperar a memória e a história do ensino técnico, referendado no Projeto de Pesquisa sobre o Ensino Profissional no Estado de São Paulo: Memória Institucional e Transformações Histórico-Espaciais, desenvolvido em parceria com o Centro Paula Souza (CPS) e o Centro de Memória da Faculdade de Educação da Universidade de São Paulo (CME/USP) e com apoio financeiro da Fundação de Apoio à Pesquisa no Estado de São Paulo (FAPESP).

Com a criação do Grupo de Estudos e Pesquisas em Memórias e História da Educação Profissional (GEPEMHEP) na Unidade de Ensino Médio e Técnico do Centro Paula Souza (CETEC/CPS), em 2008, este procedimento continuou a ser empregado nas diversas pesquisas sobre a cultura escolar.

Para aprimorar o corpo docente, a Unidade de Ensino Médio e Técnico ofereceu o curso História Oral na Educação: memórias e identidades, ministrado por Maria Lúcia Mendes de Carvalho e Suzana Lopes Salgado Ribeiro, em 2013. Durante o curso foi possível conhecer 
conceitos e pressupostos metodológicos, além de realizar oficinas sobre as práticas de entrevistas, da entrevista para a transcrição e da transcrição para as narrativas.

A história oral como metodologia “ faz parte cada vez maior de profissionais de história e outras disciplinas sociais afins. Já se reconhece a existência de uma tradição acadêmica em muitos lugares do mundo (LOZANO, 2006, p. 17)”, inclusive no Brasil, quando a partir do início dos anos de 1990 se expandiu significativamente.

Lozano (2006) destaca que a história oral,

[...] compartilha com o método histórico tradicional as diversas fases e etapas do exame histórico. De início, apresenta uma problemática, inserindo em um projeto de pesquisa. Depois, desenvolve os procedimentos heurísticos apropriados à constituição das fontes orais que se propôs produzir. Na hora de realizar essa tarefa, procede com maior rigor possível, ao controle e às criticas interna e externa da fonte construída, assim como as fontes complementares e documentais. Finalmente, passa à análise e à interpretação das evidências e ao exame detalhado das fontes recompiladas ou acessíveis. (LOZANO, 2006, p.16).

Thompson (1992), um dos pioneiros da história oral na Grã-Bretanha, já demonstrara na sua clássica obra "A voz do passado: a história oral” as potencialidades da história oral como método para o registro histórico.

\begin{abstract}
A evidência oral constitui-se em uma fonte muito importante e, muitas vezes [...] não é necessariamente um instrumento de mudança; isso depende do espírito com que seja utilizada. Não obstante, a história pode certamente ser um meio de transformar o conteúdo quanto a finalidade da história. Pode ser utilizada para alterar o enfoque da própria história e revelar novos campos de investigação; pode derrubar barreiras entre professores e alunos, entre gerações, entre instituições educacionais e o mundo exterior; e na produção da história [...] pode devolver às pessoas que fizeram e vivenciaram a história um lugar fundamental, mediante suas próprias palavras. (THOMPSON, 1992, p. 22).
\end{abstract}

Ela poderá ser utilizada, igualmente, nas afirmações do autor, "para ampliar as informações sobre acontecimentos específicos [...]" (THOMPSON, 1992, p. 112) ou "mais das vezes, o papel da evidência oral é menos sensacional, é complementar ou suplementar na reinterpretação de documentos e no preenchimento de suas lacunas e fraquezas". (THOMPSON, 1992, p. 177).

Além disso,

[...], a história oral implica, para a maioria dos tipos de história, uma certa mudança de enfoque. Assim, o historiador da educação passa a preocupar-se com as experiências dos alunos e estudantes, bem como com os problemas dos professores e administradores. (THOMPSON, 1992, p. 26). 
E, primordialmente, a história oral será útil, juntamente com outras fontes históricas, sejam escritas, materiais ou visuais, na elaboração de uma memória mais democrática do passado. (THOMPSON, 1992).

Utilizando-se das potencialidades deste procedimento, demonstrados pelos autores acima, procedeu-se a investigação do público escolar feminino no ensino agrícola em Jacareí, SP, protagonista e parte integrante do patrimônio educativo brasileiro.

Aliando a oralidade - entrevista realizada em 20 de junho de 2013, com a ex-aluna Maria Luiza Rezende - com as demais fontes como livro de matrículas, boletim de notas, jornal "O Combate", fotografias e legislações, arquivadas no Centro de Memória Etec Cônego José Bento $^{1}$, este estudo objetiva recuperar a história da turma feminina do curso de Iniciação Agrícola da Escola Profissional Mista Agrícola e Industrial Cônego José Bento (1948-1954) e a representação discente em relação à cultura escolar de uma determinada época, como as disciplinas, os professores, os espaços e os recursos pedagógicos.

O estudo pretende contribuir para a ampliação do conhecimento sobre o passado da história da Etec Cônego José Bento e do ensino técnico e profissional agrícola paulista, contexto do qual a escola fez e ainda faz parte.

\section{A TURMA FEMININA DO CURSO DE INICIAÇÃO AGRÍCOLA DA ESCOLA MISTA AGRÍCOLA E INDUSTRIAL E CÔNEGO JOSÉ BENTO (1948-1954)}

Maria Luiza Rezende ${ }^{2}$, ex-aluna da terceira turma feminina do curso de Iniciação Agrícola da Escola Agrícola e Industrial Mista Cônego José Bento, descreveu as aulas de Jardinagem.

Jardinagem... era uma maravilha! Lá prá baixo eram realizadas as aulas. Quem dava as aulas era o doutor Fernão e o doutor Castro, dava aula teórica. E o funcionário, seu Elpídio, era responsável pela jardinagem da Escola toda. Era ele de técnico e mais os funcionários braçais.

O jardim era o jardim! Vamos dizer, bem cuidado né?

\footnotetext{
${ }^{1}$ O Centro de Memória ETEC Cônego José Bento foi criado em dezembro de 2000 como um dos resultados do Projeto de Pesquisa "O ensino público profissional no Estado de São Paulo: memória institucional e transformações histórico-espaciais", desenvolvido em conjunto com o Centro de Memória da Faculdade de Educação da Universidade de São Paulo/CMFE-USP, o Centro de Educação Tecnológica Paula Souza-CEETEPS e a Fundação de Amparo à Pesquisa-FAPESP. Funciona na antiga casa do diretor e abriga diversos documentos relacionados às atividades administrativas e pedagógicas da Etec, tais como prontuários de funcionários e alunos, livros de matriculas, livros de ponto, mobiliários, instrumentos diversos, entre outros documentos.

${ }^{2}$ Brasileira, nasceu no município de Rezende, Rio de Janeiro, no dia 21 de setembro de 1936 e foi criada na fazenda Sobradinho. Na década de 1940 mudou-se, juntamente com a sua família, para Jacareí.

Ingressou aos quinze anos na Escola Agrícola e Industrial Mista Cônego José Bento e estudou de 1950 a 1952. Posteriormente, trabalhou na ETAE Cônego José Bento, no período de 1991 a 2006, na Biblioteca, onde realizou atividades como organização de acervo e atendimento.

Atualmente, aposentada, continua morando em Jacareí e dedica-se à oficina de oração e vida.
} 
$\mathrm{Na}$ aula de jardinagem se aprendia desde a preparação da terra, da plantação até o enxerto. Não havia muito, vamos dizer, paisagismo, porque na ocasião não se falava nisso ainda. Era o bom senso, aonde se achava que ficava bom isso ou aquilo. (REZENDE, 2013).

Suas lembranças conduzem ao universo feminino do ensino agrícola em Jacareí, SP: em que contexto isso ocorreu; com quais objetivos; como se organizou o currículo e quais foram as representações discente em relação à cultura escolar dessa modalidade de ensino.

O ingresso feminino no ensino agrícola foi possível com a Lei Orgânica do Ensino Agrícola, aprovada por meio do Decreto-lei 9.613, de 20 de agosto de 1946, que organizou as bases e o regime do ensino agrícola até o segundo grau e destinado essencialmente à preparação profissional dos trabalhadores da agricultura.

Os artigos 51 e 52 do referido Decreto garantiam o direito feminino ao ensino agrícola, no entanto, prescrevia algumas recomendações especiais como a não permissão para executar trabalhos inadequados a sua saúde:

Art. 51. O direito de ingressar nos cursos de ensino agrícola é igual para homens e mulheres.

Art. 52. No ensino agrícola feminino serão observadas as seguintes prescrições especiais:

1. É recomendável que os cursos do ensino agrícola para mulheres sejam dados em estabelecimentos de ensino de exclusiva frequiência feminina.

2. Às mulheres não se permitirá, nos estabelecimentos do ensino agrícola, trabalho que, sob o ponto de vista de saúde, não lhes seja adequado.

3. Na execução dos programas, em todos os cursos, ter-se-á em mira a natureza da personalidade feminina e o papel da mulher na vida do lar. (BRASIL, 1946, s.p).

\section{$\mathrm{Na}$ Escola Mista Agrícola e Industrial Cônego José Bento ${ }^{3}$ o acesso feminino ocorreu}

em 1948. A primeira turma de alunos da Escola foi composta por sessenta e cinco alunas

\footnotetext{
${ }^{3}$ A Escola Profissional Agrícola e Industrial Mista Cônego José Bento é a atual Etec Cônego José Bento, que faz parte da rede de escolas técnicas e profissionais administradas pelo Centro Estadual de Ensino Técnico e Profissional Centro Paula Souza/CEETEPS. Foi criada em 5 de julho de 1935, pelo Decreto $n^{\circ}$ 7.319, com a denominação de Escola Profissional Agrícola Industrial Mixta. O inicio de suas atividades - administrativa e escolar - só ocorreram, respectivamente, em 25 de agosto de 1936 e 27 de setembro de 1937, devido a falta de instalações.

Foi a segunda das escolas profissionais agrícolas industriais mistas a ser implantada no estado de São Paulo. Pelo Decreto 7.319, a necessidade de localizar uma escola técnica profissional servida pela Estrada de Ferro Central do Brasil e o desenvolvimento da agricultura e da pecuária na região do Vale do Paraíba Paulista, justificaram a sua criação.

Em 19 de novembro de 1940, pelo decreto $\mathrm{n}^{\circ}$ 11.588, foi atribuída à Escola o nome Cônego José Bento. A Instituição, ao longo da sua trajetória, recebeu diversas denominações, mas, desde 1940, sempre manteve o nome do patrono: Escola Profissional Agrícola e Industrial Mista (1940), Escola Prática de Agricultura (1956), Ginásio Estadual Agrícola (1964), Colégio Técnico Agrícola Estadual (1969), Escola Estadual de 2 Grau (1976), Escola Técnica Agrícola Estadual de Segundo Grau (1992), Escola Técnica Agrícola Estadual (1994), e Escola Técnica Estadual (1999).

Foi administrada por diferentes secretarias: Secretaria da Educação e Saúde Pública (1935-1955), Secretaria da Agricultura (1956-1964), Secretaria da Educação (1964-1991), Secretaria da Ciência e Tecnologia e Desenvolvimento Econômico (1992-2006) e Secretaria de Desenvolvimento Econômico (2007-atual) e ofertou modalidades distintas de ensino.
} 
regulares e onze ouvintes. Das alunas regulares, sessenta e dois moravam na zona urbana e três, na zona rural. Ao contrário dos alunos, não estudaram em regime de internato (LIVRO DE MATRÍCULAS, 1948).

A idade delas variava entre 13 e 26 anos; a maioria tinha entre 13 e 14 anos. Grande parte, trinta e dois, nasceu em Jacareí, lugar onde a Escola também se localizava; outras nasceram em São Paulo (quatro), Guaratinguetá (uma), Bragança (uma), Quiririm (uma), Guararema (duas), Chavantes (uma), Rio Preto (uma), Paraibuna (uma), Barreiro (uma), Mogi das Cruzes (uma), Nazaré (uma), Santa Izabel (uma), Taubaté (uma), Jahu (uma), Divino Espírito Santo de Itápolis (uma), Caçapava (uma), Japão (uma); e doze das alunas não declararam (LIVRO DE MATRÍCULAS, 1948).

Quarenta e seis pais das alunas da primeira turma eram de nacionalidade brasileira; cinco pais, de nacionalidade italiana; dois pais, de nacionalidade japonesa; um pai, de nacionalidade portuguesa; um pai, de nacionalidade síria; e dez pais, não declararam (LIVRO DE MATRÍCULAS, 1948).

Eles se dedicavam a diversas atividades: um era fazendeiro, dois eram agricultores, dois eram comerciantes, dois eram funcionários públicos, três eram negociantes, um era barbeiro, um era pedreiro, um era açougueiro, um era guarda civil, um era mestre de obras, um era marceneiro, um era sapateiro, um era administrador de fazenda, um era vidraceiro, oito eram lavradores, dois eram carpinteiros, três eram mecânicos, cinco eram ferroviários, um era motorista, e vinte e cinco não declararam (LIVRO DE MATRÍCULAS, 1948).

Esta primeira turma feminina, que se formou em 1950, mereceu destaque numa reportagem do jornal "O Combate”, que enalteceu as jovens.

\title{
Escola Profissional "Cônego José Bento" A Primeira Turma Feminina
}

\begin{abstract}
Receberam ontem seus diplomas as jovens que integram a primeira turma de formandas da Escola Profissional Agricola desta cidade.

As jovens que cursaram três anos naquele estabelecimento têm em suas mãos um atestado de capacidade, que por certo honrará para sempre aquela Escola Profissional, que já deu a São Paulo e ao Brasil centenas de jovens capacitados para enfrentar e resolver os problemas de sua vida, tornando-se elementos úteis à sociedade e à Pátria. $\mathrm{O}$ ensino feminino surgiu nesta Escola surgiu depois que o Prof. Arnaldo Laurindo assumiu a direção da Superintendência do Ensino Profissional. As jovens formandas receberam os ensinamentos, desde os trabalhos de agulha, até os preparativos de
\end{abstract}

Numa área de 35 alqueires, cedida pelo Bispado de Taubaté, que foi depois desapropriada pelo governo do Estado de São Paulo, a Escola foi construída e funciona até hoje. Durante décadas a Escola ofereceu apenas o curso técnico relacionado ao ensino agrícola. Nos anos de 1990 iniciou-se a expansão ofertando outros cursos e, atualmente, oferece as seguintes modalidades de ensino: Ensino Técnico: Agropecuária, Administração, Meio Ambiente, Florestas, Logística, Química e Redes de Computadores; Ensino Técnico Integrado ao Médio - ETIM; EAD Ensino à distância Administração e atende cerca de 900 alunos. 
canteiros e criação de animais e aves tão necessárias para a formação das futuras donas de casa.

$[\ldots]$

E São Paulo, na sua pujança de Estado líder, tem motivos de sobra para se orgulhar de ter dentro de sua divisão administrativa, uma cidade, embora pobre, dá ao Brasil tanta riqueza, representada por esse punhado de jovens capacitados que todos os anos saem de sua Escola Agricola, e que são os verdadeiros criadores e defensores da Pátria de amanhã que sem dúvida alguma superará a atual.

Com a formatura da primeira turma feminina desta Escola, Jacareí enche-se de orgulho, e com ela todos aqueles que militam naquela casa de ensino, isto porque, principalmente os professores e mestres, estão cumprindo um sagrado dever para com Deus e para com a Pátria. (O COMBATE, 10 dez. 1950, p. 2-4)

\section{O jornal também destacou o empenho dos professores e mestres na formação destas}

alunas:

E naquele recanto da cidade, denominado Largo do Avareí, para dentro de um simples portão, está uma plêiade de verdadeiros soldados da Pátria, dr. Fernão, dr. Antonio Martins de Castro, Profs. Messias Vicente da Cruz, Antonio S. do Nascimento, Celio Lencioni e muitos outros, inclusive os mestres das oficinas, que durante o ano todo empregaram a luz da sua sabedoria na ânsia de clarear a inteligência daqueles que lhes foram confiados no começo do ano.

E na direção do estabelecimento dois nomes se destacam, como se fossem duas gigantescas pilastras de cimento armado a suster todo o enorme peso, que outra coisa não é senão a responsabilidade de formação geral dos alunos da Escola: dr. Francisco Aparecido Ferraz Toledo, diretor, tendo ao seu lado o Prof. Ayrton S. do Nascimento, que tudo fizeram e vêm fazendo para que a Escola torne-se cada vez maior, a fim de poder atender as necessidades dos recém-diplomados pelo curso primário no Vale do Paraíba.

A exposição dos trabalhos dos alunos de ambos os sexos, levada a efeito nos anos anteriores, bem como a que se realiza neste ano nas dependências da Escola, vem atestando a dedicação e o esforço dos mestres e professores que tudo fazem, possível e o impossível para que os alunos, ao terminarem seus estudos, possam dizer lá fora, e por intermédio de sua sabedoria, que na verdade cursaram uma Escola, a Profissional Agrícola, na vida de Jacareí, que reorganizada pelo atual Superintendente de Ensino Profissional e dirigida pelo seu diretor, com a dedicação de seus diretores, está apta para receber os jovens que necessitarem de uma cultura mais elevada, sem que isso acarrete despezas a seus pais. (O COMBATE, 10 dez. 1950, p. 2-4).

O referido evento, igualmente, foi registrado na fotografia da cerimônia de formatura, que aconteceu no salão do internato da Escola Profissional Agrícola e Industrial Mista Cônego José Bento, e que contou com a presença de um grande público. 
Figura 1 - Fotografia da cerimônia de formatura no salão do internato, 1951.

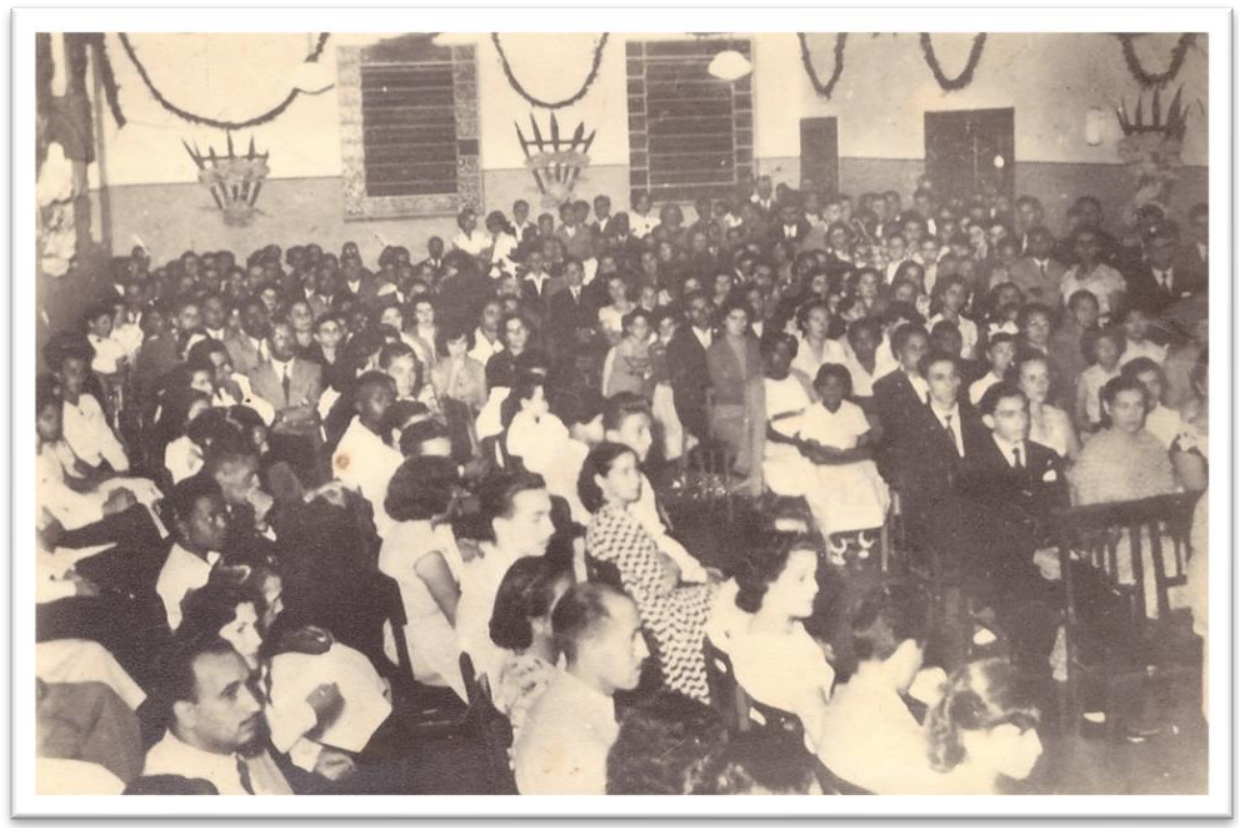

Fonte: Acervo do Centro de Memória ETEC Cônego Bento.

Durante a trajetória escolar da turma feminina na Escola Profissional Agrícola e Industrial Mista Cônego José Bento (1948 a 1954) quinze alunas foram eliminadas do curso, e todas, a pedido (LIVRO DE MATRÍCULAS, 1948).

A turma feminina de iniciação agrícola da escola seguiu o currículo estabelecido na Lei Orgânica do Ensino Agrícola, aprovada por meio do Decreto-lei 9.613, de 20 de agosto de 1946. O quadro curricular da turma feminina compreendia a parte propedêutica ou cultura geral e a técnica.

\section{O CURRÍCULO DA TURMA FEMININA DE INICIAÇÃO AGRÍCOLA}

O quadro curricular da turma feminina compreendia a parte propedêutica ou cultura geral e a técnica. Conforme Boletim de notas de Sérgia dos Santos Carneiro Pereira (cópia), de 1950, também ex-aluna da Instituição, eram estudadas na seção propedêutica, Português, Matemática, Geografia e História, Ciências, Higiene Rural e Desenho; na seção industrial, Corte e Costura e Economia Doméstica; e na seção técnica, Olericultura e Jardinagem e Zootecnia Veterinária Especializada e Apicultura. 
Figura 2 - Boletim de notas de Sérgia dos Santos Carneiro Pereira (cópia), 1950.

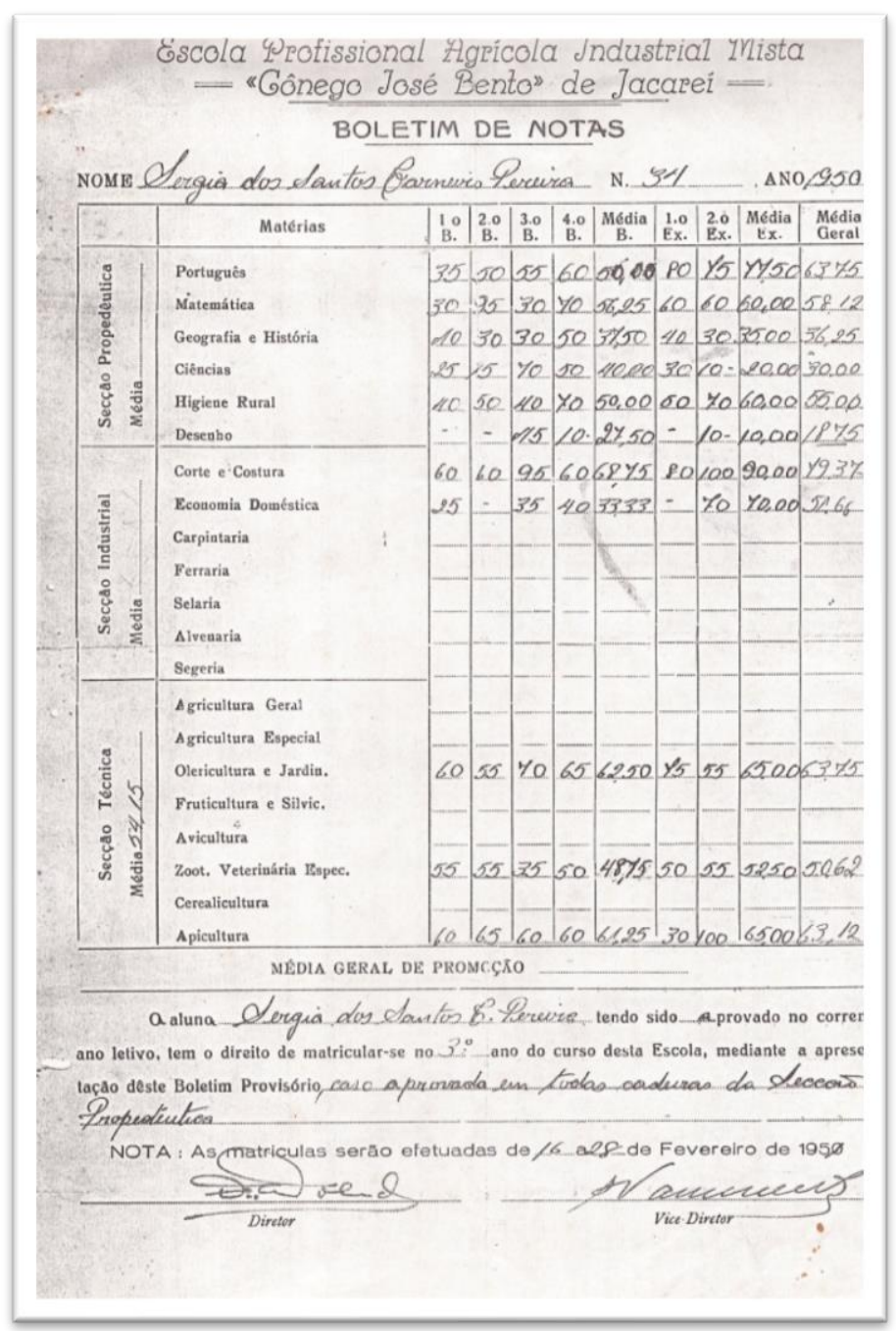

Fonte: Acervo do Centro de Memória ETEC Cônego José Bento.

Quanto à disciplina de Corte e Costura, Maria Luiza (2013) apontou que "todo material pra trabalhar era fornecido pela Escola, desde o tecido até o aviamento. Máquinas de costura, umas dez na sala de aula; eram o suficiente para atender todas as alunas". Lembrou, ainda, que as aulas eram dadas na parte que funcionou a Biblioteca, setor no qual, posteriormente, ela trabalhou como funcionária.

Durante as aulas as alunas confeccionavam uniformes da Escola toda e eles eram usados tanto na aula técnica como na aula teórica. Usava-se, diariamente, nas aulas práticas, um macacão de cor cáqui. Havia também, o que se chamava de "uniforme de festa, era uma saia pregueada, mas de um centímetro. As pregas! Prá lavar aquilo, alinhavava-se a saia toda, porque senão, não se conseguia passar depois” (REZENDE, 2013).

A mestra geral de costura era quem ensinava e acumulava a função de inspetoraalmoxarife e às alunas cabiam aprender a costurar para serem eficientes donas de casa. As peças 
confeccionadas por elas eram expostas em eventos anuais, promovidas pela Escola, na própria instituição ou no centro da cidade de Jacareí, como se visualiza pela Figura 3, a seguir.

Figura 3 - Fotografia das peças confeccionadas pelas alunas durante as aulas de corte e costura, apresentadas na exposição do final de ano de 1952.

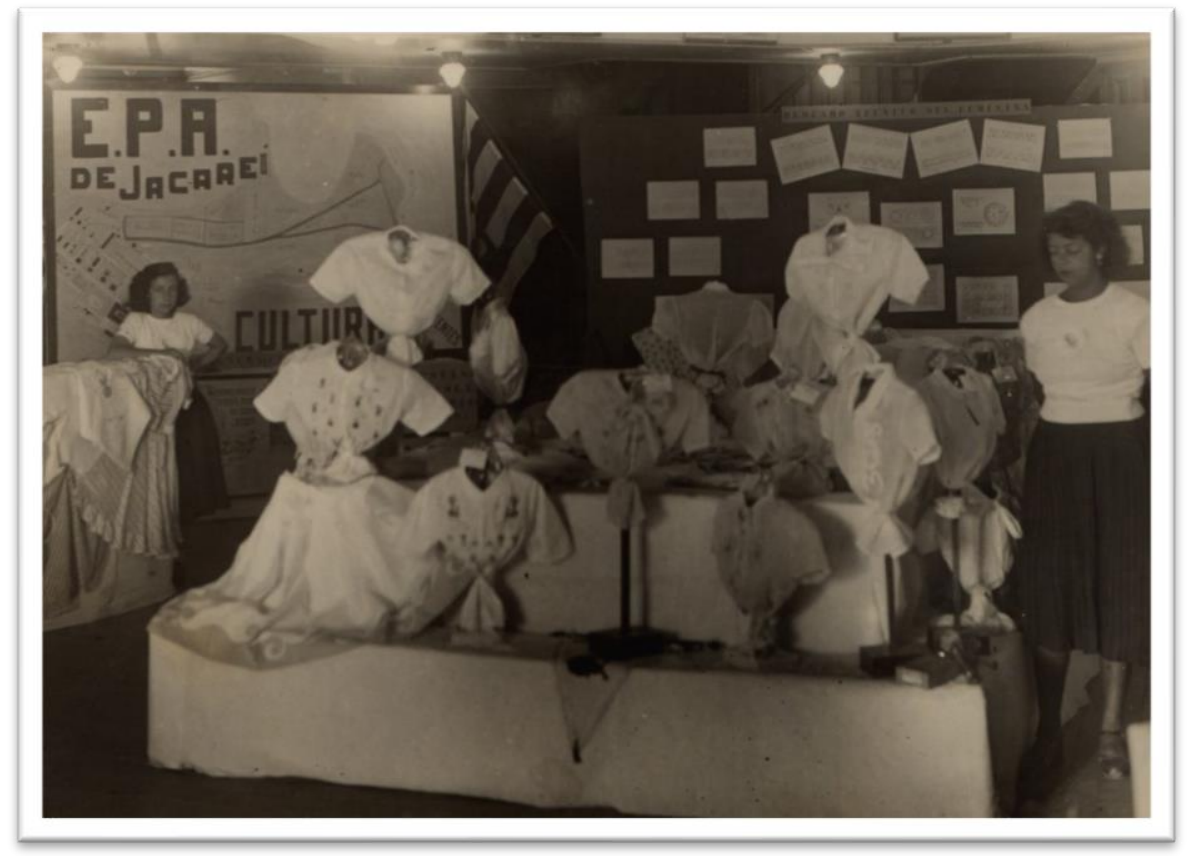

Fonte: Acervo do Centro de Memória ETEC Cônego José Bento.

Nas aulas de Economia e Artes Domésticas, as alunas aproveitavam todos os produtos agrícolas produzidos na escola. Em razão da educação doméstica, as alunas praticavam as atividades rurais relacionadas à jardinagem, olericultura - legumes de folhas e frutos -, avicultura, dentre outros.

Direcionadas para o feminino tínhamos Economia Doméstica, que era bem abrangente, inclusive, saber administrar uma casa completamente, fazer desde o orçamento doméstico até o controle, por exemplo, de roupas que mandava para lavanderia e por aí afora. Era a administração de uma casa, com tudo que isso implica. Era uma profissionalização da dona de casa. (REZENDE, 2013).

O artigo 52 da Lei Orgânica do Ensino Agrícola, aprovada pelo Decreto-Lei ${ }^{\circ}$ 9.613, de 20 de agosto de 1946, estabelecia no seu parágrafo $4^{\circ}$ que "os dois cursos de formação do primeiro ciclo, incluir-se-á o ensino de economia rural doméstica”.

Maria Luiza Rezende (2013) afirmou que a apicultura era uma disciplina que ela e suas colegas gostavam muito. O professor de aula teórica era Daniel Zilli, muito conceituado e conhecido na cidade, e a aula prática, era dada por Roberto Godoy, que mais tarde se tornaria diretor da Escola.

Nas aulas de avicultura, a ex-aluna recorda que 
[...] lidava-se com todas as etapas, separava os piquetes de poedeiras, todo o processo que existe na área, e a aula teórica era dada pelo professor Antoninho Nunes, que mais tarde se tornou prefeito de Jacareí.

As separações dos ovos eram por tamanho e feitas embaixo do prédio administrativo; era tudo muito limpinho, sempre pintado. Havia uma preocupação com a segurança e com a higiene. (REZENDE, 2013).

$\mathrm{Na}$ disciplina de Olericultura, as alunas aprendiam sobre os procedimentos adequados ao cultivo e colheita de hortaliças; as aulas ocorriam no setor específico, conforme indica o depoimento de Rezende (2013).

\begin{abstract}
As aulas na horta, era lá embaixo, bem lá prá baixo mesmo, pra cá do estábulo; em uma extensão muito grande, bem grande mesmo. Quem ministrava as aulas teóricas eram o doutor Fernão e o doutor Castro e a aula prática era o professor Moura, Francisco de Moura, muito querido por todos.

Na horta plantava-se hortaliças de modo geral, alface, chicória, muita couve. Plantavase também mandioca e abóbora. (REZENDE, 2013).
\end{abstract}

Na matéria de Jardinagem se cultivava flores, principalmente orquídeas. O orquidário para Rezende (2013) era uma

[...] coisa maravilhosa! Existia ambiente, tudo fechado com ripado entendeu? A orquídea pede sol e sombra, e dava bem; teve boas produções.

O conhecimento das orquídeas, quem possuía era o doutor Fernão, o seu Elpídio, o seu Moura. Enfim, havia entre as disciplinas e entre os professores... um intercâmbio, uma integração. Já ocorria uma integração, que hoje damos o nome de interdisciplinar. (REZENDE, 2013).

E, no apiário, no processo de ensino e de aprendizagem “[...] colhíamos o mel e já trazia pra centrifugar, engarrafar. E, havia a sala com mesa e bancos para as aulas teóricas. Qualquer coisa que precisasse anotar durante a aula prática, existia lugar para anotar" (REZENDE, 2013).

O currículo determinou os tipos de instalações para o ensino agrícola. Além das salas de aula, foram projetadas construções em ambientes diferentes. Cada uma delas previa equipamentos e materiais específicos para atender as disciplinas das seções técnica e industrial.

O Decreto-lei 9.613, de 20 de agosto de 1946 reafirma no seu artigo 64 que, para a validação do funcionamento dos estabelecimentos de ensino agrícola, eles teriam que satisfazer a construção de edifício ou edifícios que utilizarem.

Pelo depoimento de Rezende (2013) e pela fotografia das alunas no aviário, a seguir, no período que a Instituição atendeu ao público feminino (1948-1954), observa-se que as construções e espaços atenderam ao que estava previsto no referido Decreto-lei.

Para a ex-aluna do curso de Iniciação Agrícola, “[...] todas as estruturas, as construções, naquela ocasião, atendiam as necessidades da aula” (REZENDE, 2013). 
Figura 4 - Fotografia das alunas no aviário, 18 de agosto de 1948.

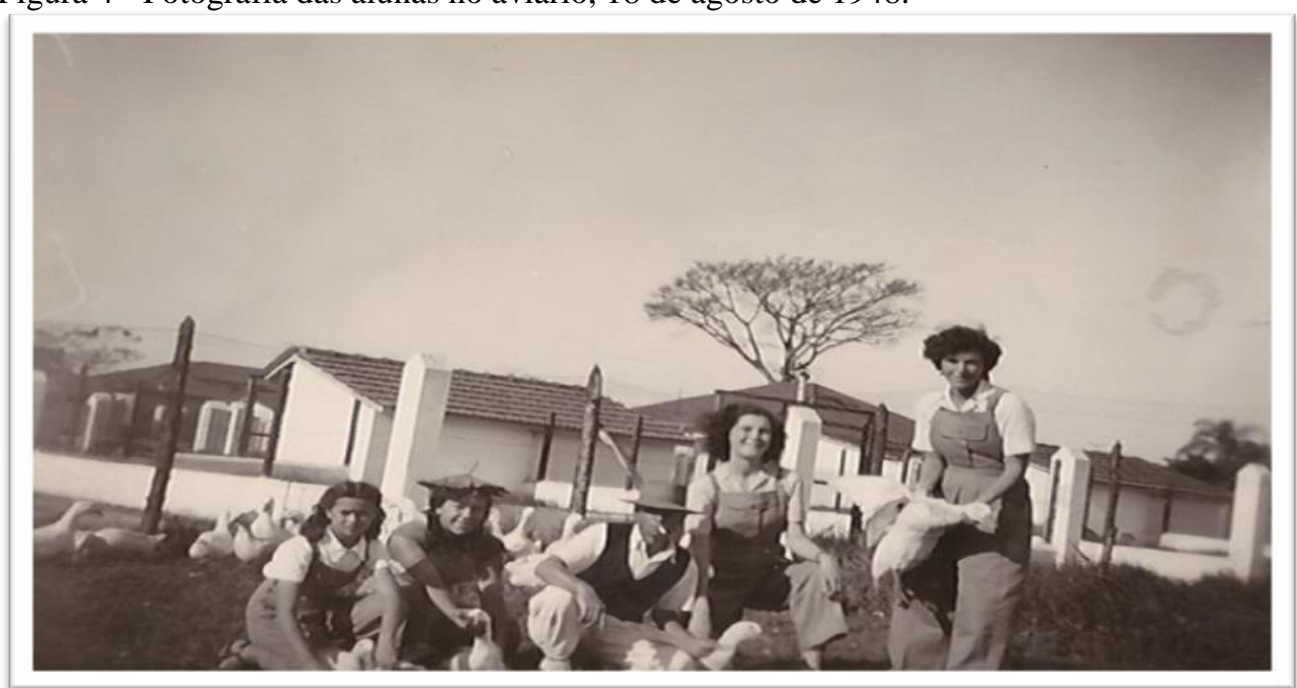

Fonte: Acervo do Centro de Memória ETEC Cônego José Bento.

Quanto aos materiais pedagógicos,

[...] todos os materiais para as aprendizagens do ensino técnico, eram disponibilizados pela Escola. Quer dizer, de repente, um professor sentia falta de alguma coisa, mas nós alunos, achávamos que estava tudo bem, que estava atendendo muito bem. Por exemplo, no caso do manuseio das abelhas que necessitavam de roupas especiais, tinha tudo; todo o equipamento que precisava. (REZENDE, 2013).

Assim, Rezende (2013) registrou suas impressões, vivências e lembranças sobre o cotidiano escolar da época em que ela estudou na Escola Profissional Agrícola e Industrial Cônego José Bento, entre 1950 e 1952.

A sua entrevista, ainda que cunhada pela subjetividade, forneceu informações válidas como testemunho, assim como qualquer outra fonte. Ajudou a compreender melhor o contexto do ensino agrícola paulista e revelou, por meio de suas memórias, aspectos da cultura escolar de uma determinada época.

Como defendeu Thompson (1992, p. 195), “o valor histórico do passado lembrado [...] pode proporcionar, e de fato proporciona, informação significativa e, por vezes, única sobre o passado".

Desta forma, este estudo recuperou parte da memória e história do ensino técnico e profissional agrícola paulista, especificamente, em Jacareí-SP, por meio da história oral, além de outros documentos, expondo a cultura escolar de uma determinada época, como as disciplinas, os professores, os espaços e os recursos pedagógicos. 


\section{CONSIDERAÇÕES FINAIS}

A história oral possibilitou, juntamente com outras fontes históricas, expandir as informações de um determinado fato e período da história da Escola Profissional Agrícola e Industrial Mista de Jacareí: a turma feminina do curso de Iniciação Agrícola, de 1948 a 1954; assinalou as impressões, vivências, lembranças discentes sobre a cultura escolar de uma época; e recompôs parte da memória e história do ensino técnico e profissional agrícola paulista.

Outros documentos, como a Lei Orgânica do Ensino Agrícola, por meio do Decretolei 9.613, de 20 de agosto de 1946, elucidaram quando e como, legalmente, se garantiu à mulher o direito de ingressar no ensino agrícola, bem como as recomendações quanto ao ensino, que deveria ser ministrado em estabelecimentos de exclusiva frequência feminina. Na Escola Profissional Agrícola e Industrial Mista Cônego José Bento isso ocorreu de forma mista, como estabeleceu o artigo 855 do Decreto ${ }^{\circ} 17.698$, de 26 de novembro de 1947.

Em todo o curso, deveria ser considerada a natureza da personalidade feminina e o papel da mulher no lar, o que justifica a inclusão do ensino de economia rural doméstica. Era importante para as meninas, futuras donas de casa, terem em seu currículo escolar uma disciplina que oferecesse os conhecimentos relacionados ao papel da mulher.

O livro de matrículas (1948), o boletim de notas de Sérgia dos Santos Carneiro Pereira (1950), as fotografias - do evento da formatura (1951), das alunas no aviário (18/08/1948) e da exposição do final de ano (1952) - e o jornal "O Combate" (10 dez. 1950), por sua vez, indicaram qual foi o currículo estabelecido para a turma feminina e os aspectos dos saberes e fazeres escolares.

Cabe ressaltar que a fonte oral, assim como as demais, é subjetiva, que requer do pesquisador da História da Educação rigor na sua análise. Muitas vezes, o testemunho oral representa o caminho possível para reconstruir a memória da história vivida no universo escolar.

Maria Luiza Rezende, por meio da sua oralidade, colaborou para alargar o conhecimento sobre o passado da história da Escola Profissional Agrícola e Industrial Mista Cônego José Bento, notadamente da turma feminina. O seu testemunho também se constitui como parte do patrimônio educativo, preservado no Centro de Memória Cônego José Bento, podendo revelar novos campos de investigação. 


\section{REFERÊNCIAS}

BOLETIM de notas de Sergia dos Santos Carneiro Pereira (cópia), 1950. Acervo Centro de Memória Etec Cônego José Bento.

BRASIL. Decreto-Lei no 9.613, de 20 de agosto de 1946. Lei Orgânica do Ensino Agrícola. Rio de Janeiro, 1946.

Decreto-Lei $n^{0}$ 9.614, de 20 de agosto de 1946. Disposições transitórias para execução da Lei Orgânica do Ensino Agrícola. Rio de Janeiro, 1946.

CARVALHO, M. L. M. de; RIBEIRO, S. L. S. História oral na educação: memórias e identidades. São Paulo: Centro Paula Souza, 2013.

FOTOGRAFIA das alunas no aviário, 18 de agosto de 1948. Acervo Centro de Memória Etec Cônego José Bento.

FOTOGRAFIA da cerimônia de formatura no salão do internato, 1951. Acervo Centro de Memória Etec Cônego Bento.

FOTOGRAFIA das peças confeccionadas pelas alunas durante as aulas de corte e costura e apresentadas na exposição do final de ano, 1952. Acervo Centro de Memória Etec Cônego José Bento.

LOZANO, J. E. A. Prática e estilos de pesquisa na história oral contemporânea. In: FERREIRA. M. de M.; AMADO, J. (Orgs.). Usos e abusos da história oral. 8. ed.. Rio de Janeiro: FGV, 2006, p. 15-25.

LIVRO DE MATRÍCULA da Secção Feminina da Escola Profissional Agricola Industrial Mista Cônego Jose Bento. 1948. Acervo do Centro de Memória Etec Cônego José Bento.

O COMBATE. Jornal. 10 dez. 1950, n. 3, ano 1, p. 2-4. Acervo do Centro de Memória Etec Cônego José Bento.

REZENDE, M. L. Entrevista concedida a autora do estudo em 20 de junho de 2013. Acervo do Centro de Memória Etec Cônego. José Bento.

SÃO PAULO. Decreto n ${ }^{\circ} 17.698$, de 26 de novembro de 1947. Consolidação das leis e demais normas relativas ao ensino, 1947.

THOMPSON, P. A voz do passado: a história oral. Tradução de Lólio Lourenço de Oliveira. 3. ed.. Rio de Janeiro: Paz e Terra, 1992. 